\title{
Contributing Factors of Substance Abuse among Secondary Level School Students in Bharatpur Metropolitan
}

\author{
Alisha Gurung ${ }^{1}$, Hari Prasad Kaphle ${ }^{1}$ \\ ${ }^{1}$ School of Health and Allied Sciences, Pokhara University, Pokhara-30, Kaski, Nepal
}

\begin{abstract}
Introduction: Substance abuse is harmful or hazardous use of psychoactive substance including alcohol, tobacco and illicit drugs. This study aimed to assess the prevalence and contributing factors for substance abuse among secondary level school students in Bharatpur Metropolitan.
\end{abstract}

Methods: A cross sectional study was carried out among 495 students of grade 11 and 12 of secondary schools in Bharatpur metropolitan from June to December, 2019. Data were collected using self-administered anonymous questionnaire. Chi-square test was performed to find out the association between dependent and independent variables and crude odd ratio was obtained to measure the strength of association.

Results: The study showed that $18.8 \%$ participants were involving in substance abuse. Alcohol was found to be most commonly abused substance by participants. Substance abuse was significantly associated with boys (OR=11.903, 95\% CI: 6.395-22.157), high monthly household income (OR=1.709, 95\% CI: 1.085-2.691), time spent on internet more than one hour per day $(\mathrm{OR}=2.401,95 \% \mathrm{CI}: 1.388-4.153)$, no control over internet by others $(\mathrm{OR}=2.578,95 \%$ $\mathrm{CI}: 1.574-4.224)$, management students $(\mathrm{OR}=1.678,95 \% \mathrm{CI}: 1.011-2.286)$, absence in school for more than 4 days in a month $(\mathrm{OR}=2.401,95 \% \mathrm{CI}: 1.338-4.153)$, students living with others than family members $(\mathrm{OR}=2.577,95 \% \mathrm{CI}: 1.339$ 4.958), presence of substance abuser in family $(\mathrm{OR}=2.701,95 \% \mathrm{CI}: 1.667-4.377)$, sibling abuse substances $(\mathrm{OR}=4.757$, 95\% CI:1.467-15.248), substance abuser in close friend circle (OR=11.204, 95\% CI: 6.693-4.18.755), friends insisted/ enforced to take substances $(\mathrm{OR}=2.978,95 \% \mathrm{CI}: 1.409-6.294)$, substance abuser in neighborhood $(\mathrm{OR}=2.866,95 \%$ CI:1.777-4.621) and stressful events (OR=2.434, 95\% CI: 1.130-5.243).

Conclusion: Various socio-demographic, socio-economic, technological, educational, environmental and psychological factors play significant role in substance abuse among secondary school students. It is recommended to observe and monitor activities of adolescents regularly, provide a suitable and supportive environment to adolescents and provide school, community and health facility based awareness, counseling and services to solve the problem of substance abuse among adolescents.

Keywords: Substance abuse, secondary school students and factors associated.

\section{INTRODUCTION}

According to World Health Organization (WHO), "substance abuse is harmful or hazardous use of psychoactive substance including alcohol and illicit drugs". ${ }^{1}$ Some of the abused substance includes alcohol, cigarette/tobacco, cannabis, amphetamines, marijuana, ecstasy, opioids, cocaine etc. Likewise, it also includes khat, inhalants and volatile substances like glue, petrol and also synthetic drugs like barbiturates. Substance abuse has become a major public health problem in global context and it has been increasing drastically in developing countries. ${ }^{23}$ Adolescence substance abuse holds a number of negative health consequences and has also negative impact on wellbeing of individual. It also increases risk of injury, suicidal ideations, decreased academic performance, risk of acquiring STDs and psychiatric disorders. ${ }^{2,4}$

Similarly, it also leads to social consequences as well as poverty which affect economic status of country. ${ }^{5}$ There is also a link between substance abuse and getting involved in a crime. ${ }^{4}$

Adolescence are vulnerable to substance abuse and have greater problems regarding substance abuse. It is a common public health risk that peaks in age of 18-25 years and are highly prevalent in school students. ${ }^{6}$ Factors affecting substance abuse among adolescents are numerous and complex in different context. ${ }^{7}$ Adolescent substance abuse has been associated with low academic performance, declining grades, absenteeism, and school drop-out. ${ }^{4}$

Different study showed different prevalence of substance abuse

Correspondence: Dr. Hari Prasad Kaphle, School of Health and Allied Sciences, Pokhara University, Pokhara-30, Kaski, Nepal E-mail-harikafle07@gmail.com 
among school adolescent. The lowest prevalence was reported in a study conducted in Kaski district of Nepal (6.3\%) and highest prevalence was reported in a cross sectional study conducted in nine secondary schools of Western Kenya (64.4\%). ${ }^{6} 8$ Studies from India showed prevalence of substance in between 12.5$34.9 \%$ among adolescents. ${ }^{9-11}$

A recent study in Kaski district of Nepal showed only 6.3\% adolescents were involving in substance abuse. Similarly, another recent study from western Nepal showed that $10.5 \%$ adolescents were involving in tobacco use and $22.3 \%$ in alcohol and other intoxicants. ${ }^{12}$ Moreover, a study conducted in Kalaiya, Nepal reported that $25.3 \%$ adolescents were involving in use of tobacco products (boys-31.0\%, girls- 14.4\%). ${ }^{13}$ A survey report on current hard drug users in Nepal (2069) showed that among substance abusers in Nepal, 19.9\% were of age group of 15-19 years. ${ }^{14}$ The aim of this study was to determine the prevalence and contributing factors for substance abuse among secondary school students in Bharatpur Metropolitan.

\section{METHODS}

A cross sectional study was carried out among secondary level school students of Bharatpur Metropolitan of central Nepal in between June to December 2019. A sample size of 495 students studying in grade 11 and 12 was determined based on the sampling formula $n=\left[z^{2} p q / d^{2}(n-1)+z^{2} p q\right] D E F E$ with $95 \%$ confidence interval, $5 \%$ margin of error, 6020 sample population, 1.5 design effect and 34.93\% prevalence of substance abuse in a study conducted in India. ${ }^{11}$ Among 39 secondary schools having grade 11 and 12 in Bharatpur metropolitan, 13 schools were selected by simple random sampling. Similarly, from each selected school one stream and from each stream one particular class was selected by simple random sampling. All the students of the selected classes whose parents/guardians provided consent for their participation were included for the study.

Pretested self-administered anonymous questionnaire constructed in both English and Nepali languages was used to collect information. To minimize the reporting bias, every participant was clearly informed about purpose of study and ensured about maintaining the privacy and confidentiality of obtained information. Substance abuse was the dependent variable which was operationally defined as use of alcohol, cigarette/tobacco, charas (brown sugar), cannabis, heroin, khat, sisha, inhalants (glue) at least once in one year prior to date of data collection. There were 33 independent variables of sociodemographic (sex, age, residence, religion, family type, father's education, mother's education, parent's marital status, prosocial involvement), economic (father's occupation, mother's occupation, frequency of receiving pocket money, monthly household income), technological (access of internet, time spent on internet, control over internet by others), educational (type of school, type of discipline, grade studying, grade achieved in last year, days of absence in 30 days, inspection by school, involvement in extracurricular activities within 30 days), environmental (current place of stay, living arrangement, substance abuser in family, person with substance abuse in family, substance abuser in close friends, friends insists to take substance, access to alcohol shop, substance abuser in neighborhood) and psychological factors (self-esteem, stressful events). Self-esteem was measured by a 12 item instrument Rosenberg self-esteem scale (Cronbach's alpha=0.73 during pretesting).

Collected data were coded and entered in EpiData and extracted into Statistical Package for Social Science (SPSS) for further analysis. Descriptive statistics were reported as percentage and frequencies. In addition, chi-square test was applied to find out the association between dependent and independent variables and crude odds ratio was obtained by binary logistic regression analysis to show the strength of association. This study was approved by Public Health Program, School of Health and Allied Sciences, Pokhara University and ethical approval was obtained from Institutional Review Committee (IRC) of Pokhara University Research Center. Written approval for conducting study was taken from the administration of all selected schools. Informed written consent was obtained from each participant and their parents/guardians and confidentiality of the received information was maintained.

\section{RESULTS}

Socio-Demographic Characteristics: Out of 495 students, more than half of the students $(56.2 \%)$ were females. Most of the students $(69.3 \%)$ were of above 17 years. Similarly, about threequarter $(74.5 \%)$ were belong to urban areas. Likewise, about two-third of the participants $(65.7 \%)$ were belong to nuclear family. Similarly, Hindu was the most followed religion (87.7\%) among participants. In addition, more than half (60.6\%) were belong to upper caste groups. Most of the participant's father $(33.5 \%)$ and mother $(30.1 \%)$ had secondary level of education. In addition, majority of participants (94.3\%) were living together with their families (table 1).

Table 1: Socio-demographic characteristics of respondents $(\mathrm{n}=495)$

\begin{tabular}{lcc}
\hline Variables & $\begin{array}{c}\text { Frequency } \\
(\mathrm{n})\end{array}$ & $\begin{array}{c}\text { Percent } \\
(\%)\end{array}$ \\
\hline Sex & & \\
Male & 217 & 43.8 \\
Female & 278 & 56.2 \\
Age & & \\
$<17$ Years & 152 & 30.7 \\
\hline
\end{tabular}


$\geq 17$ Years

343

69.3

$\operatorname{Min}=15, \operatorname{Max}=22$, Mean=17.11, Median=17, S.D. \pm 1.140

Permanent residence

Rural

126

25.5

Urban

Family type

Nuclear

325

Joint

161

Extended

Religion

Hindu

Buddhist

Muslim

Christian

Ethnicity

Dalit

Disadvantaged Janajati

Disadvantaged Non- Dalit Terai Caste Group

Religious Minorities

Relatively Advantaged Janajati

Upper Caste Group

Father's education level

Illiterate

Non formal education

Basic education

Secondary education

Bachelor

Master and above

Mother's education level

Illiterate

Non formal education

Basic education

Secondary education

Bachelor

Master and above

Parent's marital status

Living together

Divorced

Father/Mother deceased

Living separately

$\begin{array}{ll}9 & 1.8\end{array}$

434

87.7

9.9

0.4

2.0

10

54

67

20

2

52

52

300

26

86

$106 \quad 21.4$

$166 \quad 33.5$

$64 \quad 12.9$

47

9.5

49

9.9

$118 \quad 23.8$

$149 \quad 30.1$

$53 \quad 10.7$

$15 \quad 3.0$

$467 \quad 94.3$

$6 \quad 1.2$

$\begin{array}{ll}7 & 1.4\end{array}$

15
$111 \quad 22.4$
Prevalence of substance abuse: About one in five respondents (18.8\%) were engaged in substance abuse within last 12 months. Among 93 participants who were engaged in substance abuse in last 12 months, maximum 95.7\% were using alcohol followed by cigarette/tobacco and only $1.1 \%$ used heroin and inhalants (table 2).

Table 2: Prevalence of substance abuse $(n=495)$

\begin{tabular}{lcc}
\hline Variables & Frequency $(\mathrm{n})$ & Percent $(\%)$ \\
\hline Substance abuse & & \\
Yes & 93 & 18.8 \\
No & 402 & 81.2 \\
Type of substances (n=93) & & \\
Alcohol & 88 & 95.7 \\
Cigarette/tobacco & 44 & 47.8 \\
Cannabis & 22 & 23.9 \\
Charas & 2 & 2.2 \\
Khat & 7 & 7.6 \\
Sisha & 17 & 18.5 \\
Heroin & 1 & 1.1 \\
Inhalants & 1 & 1.1 \\
\hline
\end{tabular}

Factors associated with substance abuse: Out of 33 independent variables tested, 15 variables were found significantly associated with substance abuse among secondary school students in Person's chi-square test. However after obtaining crude odd ratio (COR) in binary logistic regression analysis, only 13 variables were associated with substance abuse. Substance abuse was significantly associated with male students, high monthly household income, time spent on internet more than one hour, no control over internet by others, management stream students, absence from school for more than 4 days in a month, students living with others than family members, presence of substance abuser in family, sibling abuse substances, substance abuser in close friend circle, friends insisted/enforced to take substances, substance abuser in neighborhood and stressful event like death event (table 3).

Table 3: Factors associated with substance abuse among secondary school level students of Bharatpur Metropolitan(n=495)

\begin{tabular}{|c|c|c|c|c|c|c|}
\hline \multirow{2}{*}{ Variables } & \multicolumn{2}{|c|}{ Substance abuse } & \multirow{2}{*}{$\chi^{2}$} & \multirow{2}{*}{$\begin{array}{c}\mathrm{P} \\
\text { Value }\end{array}$} & \multirow{2}{*}{ COR } & \multirow{2}{*}{$95 \% \mathrm{CI}$} \\
\hline & Yes (\%) 93 (18.8) & No (\%) 402 (81.2) & & & & \\
\hline \multicolumn{7}{|l|}{ Sex } \\
\hline Male & $80(36.9)$ & $137(63.1)$ & 82.765 & $<0.001^{*}$ & 11.903 & $6.395-22.157$ \\
\hline Female & $13(4.7)$ & $265(95.3)$ & & & 1 & \\
\hline
\end{tabular}




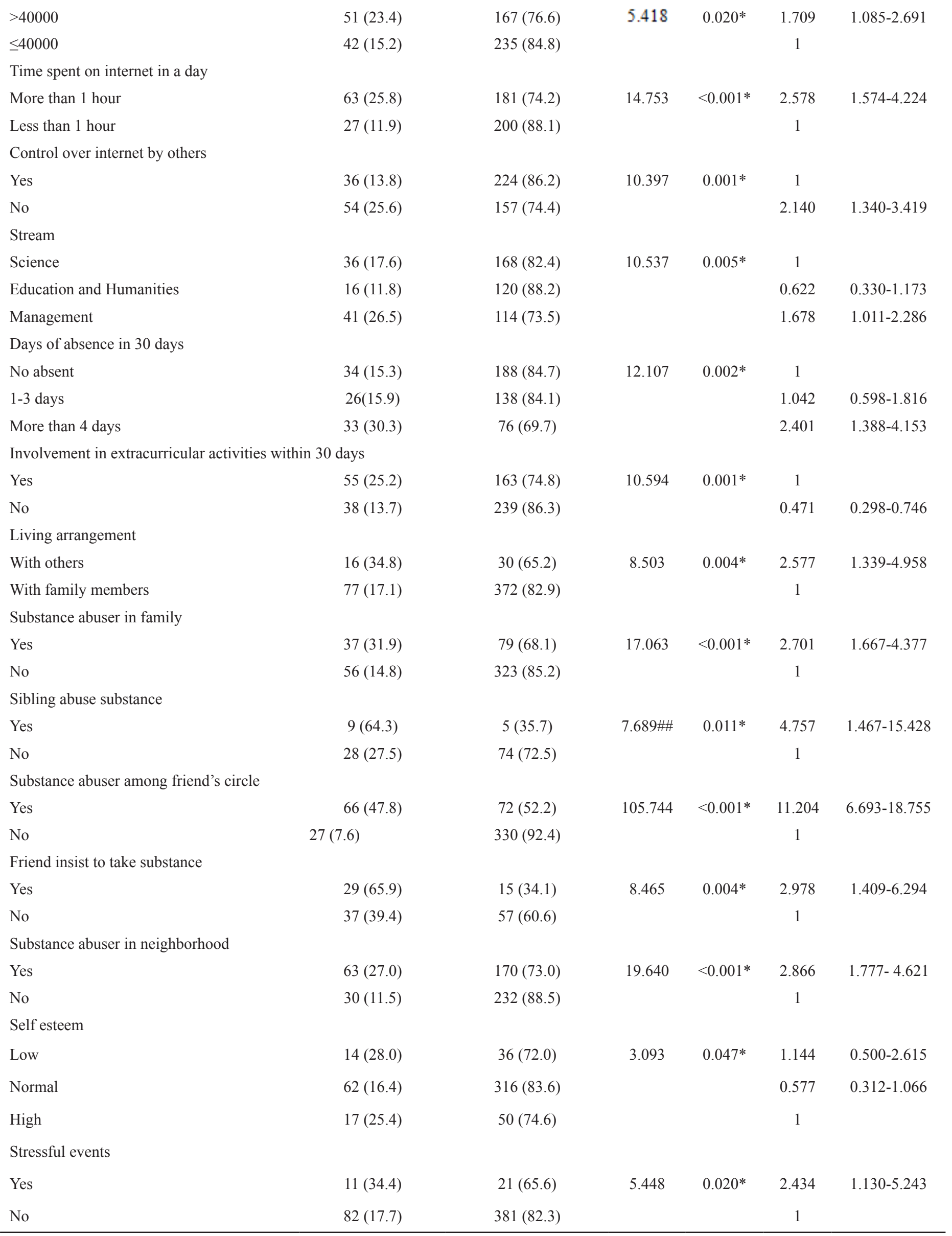

*statistically significant at $(\mathrm{p}<0.05)$,\#\#Fisher's Exact Test 


\section{DISCUSSION}

In this study, the prevalence of substance abuse among secondary school students was found $18.8 \%$ which is somewhat similar with the studies conducted in Brazil (17.1\%) and Thailand $(17.7 \%)^{3,15}$ However, it is higher than another study conducted in Nepal $(6 \%) .{ }^{6}$ The reason behind it may be that author assessed in only one school with few substances in that study. The prevalence of substance abuse in this study was slightly lower as compared to other studies conducted in India, Brazil, Ethiopia, Mexico, Kenya, US. ${ }^{8,9,11,16-19}$ The possible reason could be due to difference of lifestyle in countries.

The present study revealed sex as the factor contributing of substance abuse in secondary school students where male students were about twelve times ( $\mathrm{OR}=11.903,95 \% \mathrm{CI}$ : 6.395 22.157, $\mathrm{p}<0.001)$ more likely to abuse substances compared to female students which is similar to the findings of other studies conducted in different parts of the world. ${ }^{2,19-21}$ But it contrast to a study conducted in Brazil. ${ }^{16}$ This indicate male students are at greater risk for substance abuse

Higher the monthly household income, higher the chances of substance abuse $(\mathrm{OR}=1.709,95 \% \mathrm{CI}$ : 1.085-2.691, $\mathrm{p}<0.020)$ among secondary school students was observed in this study, which is similar to the study conducted in Saudi Arabia. ${ }^{22}$ This could be due to higher access to money among adolescents among households with higher income.

It was also observed that students from management stream were more likely to involve in substance abuse $(\mathrm{OR}=1.678,95 \% \mathrm{CI}$ : 1.011-2.286, $\mathrm{p}=0.005$ ) compared to student from science stream. A study conducted in Nigeria reported that students from art and social science were about two times more likely to abuse substance than science. ${ }^{23}$ However, no evidence was found regarding comparison between management and science stream. It was observed that students who were more than 4 days absent in school in past 30 days were about two and half times more likely to be engaged in substance abuse $(\mathrm{OR}=2.401,95 \% \mathrm{CI}$ : $1.388-4.153, \mathrm{p}<0.001)$ than who never absent in school in past 30 days which is similar to the study conducted in Brazil. ${ }^{16}$ Students who used to absent in class frequently may involve in high risk activities like substance abuse.

In this study, environmental factors like living arrangement, substance abuser in family, substance abuse by sibling, substance abuser in close friend, insist from friend to take substance and substance abuser in community were also found statistically significant with substance abuse.

Students who were residing with others than family members were more than 2 times higher $(\mathrm{OR}=2.577,95 \% \mathrm{CI}$ : 1.339 -
4.958, $\mathrm{p}=0.004$ ) risk of substance abuse which is similar to the studies conducted in India. Several studies conducted in Nepal, India, Ethiopia, Thailand shows significant association between substance abuser presence in family and substance abuse among students and reported having substance abusers in family are more likely to be substance abusers. 2, 6, 9, 15,21 It was observed that students who had siblings who use substances were more likely to engage in substance abuse $(\mathrm{OR}=4.757,95 \% \mathrm{CI}$ : 1.467 $15.428, \mathrm{p}=0.011$ ) which is line with the findings of three studies conducted in Ethiopia., 17, 24 Likewise, it was observed students having substance abuser in close friend circle were likely to be more engaged in substance abuse $(\mathrm{OR}=11.204,95 \% \mathrm{CI}$ : 6.693-18.755, $\mathrm{p}<0.001$ ) and shows positive association which is consistent to the studies conducted in Ethiopia and India. ${ }^{2,9}$ In addition, it was observed that peer pressure (friends insist to take substance) was associated with more likely to abuse substances among students $(\mathrm{OR}=2.978,95 \% \mathrm{CI}$ : 1.409-6.294, $\mathrm{p}=0.004)$ which is similar with findings of the studies conducted in Mexico and Ethiopia. ${ }^{18,25}$ Likewise, substance abuser in neighborhood was also found as a significant factor $9 \mathrm{OR}=2.866,95 \% \mathrm{CI}$ : 1.777- 4.621, $\mathrm{p}<0.001)$. These all indicate that adolescent's life style is directly influenced by their surrounding where they live, to whom they live with and to whom they interact with.

\section{CONCLUSION}

The study concluded various socio-demographic, socioeconomic, technological, educational, environmental and psychological factors play significant role in substance abuse among secondary level school students. It is recommended to observe and monitor the activities of adolescents regularly, provide a suitable and supportive environment from their parents, family members, community and school. Community, health facility and school based awareness, counselling and services for adolescents are also crucial to reduce substance abuse among school adolescents

\section{REFERENCES}

1. World Health Organization. Substance abuse 2019 [cited 2019 Sept 20]. Available from: https://www.who.int/ topics/substance_abuse/en/.

2. Birhanu AM, Bisetegn TA, Woldeyohannes SM. High prevalence of substance use and associated factors among high school adolescents in Woreta Town, Northwest Ethiopia: multi-domain factor analysis. BMC Public Health. 2014;14(1):1186.

3. Tavares BF, Béria JU, Lima MSd. Factors associated with drug use among adolescent students in southern Brazil. Revista de saude publica. 2004;38(6):787-96.

4. Poorasl AM, Vahidi R, Fakhari A, Rostami F, Dastghiri 
S. Substance abuse in Iranian high school students. Addictive behaviors. 2007;32(3):622-7.

5. Tshitangano TG, Tosin OH. Substance use amongst secondary school students in a rural setting in South Africa: Prevalence and possible contributing factors. African journal of primary health care \& family medicine. 2016;8(2):1-6.

6. Gurung A, Shrestha N, Silwal M, Gurung R, Ojha S. Prevalence of substance use and associated factors among high school adolescents in Rithepani, Lekhnath-2, Kaski, Nepal. Journal of Gandaki Medical College-Nepal. 2017;10(1):43-8.

7. Riva K, Allen-Taylor L, Schupmann WD, Mphele S, Moshashane N, Lowenthal ED. Prevalence and predictors of alcohol and drug use among secondary school students in Botswana: a cross-sectional study. BMC public health. 2018;18(1):1396.

8. Otieno A, Ofulla A. Drug abuse in Kisumu town western Kenya. African Journal of Food, Agriculture, Nutrition and Development. 2009;9(3):847-58.

9. Thakur S, Parashar A, Dhadwal DS, Mahajan A. Prevalence and correlates of substance abuse among school going adolescents in a hilly district of himalayan region in India. J Evid Based Med Healthc. 2017;4(72):4278-85.

10. Tsering D, Pal R, Dasgupta A. Substance use among adolescent high school students in India: A survey of knowledge, attitude, and opinion. Journal of Pharmacy and Bioallied Sciences. 2010;2(2):137.

11. Qadri S, Goel R, Singh J, Ahluwalia S, Pathak R, Bashir H. Prevalence and pattern of substance abuse among school children in northern India: A rapid assessment study. Int J Med Sci Public Health. 2013;2(2):273-82.

12. Karki S, Länsimies H, Laukkanen E, Pirskanen M, Pietilä A-M. Substance use by adolescents in the Western Developmental Region of Nepal. Journal of Substance Use. 2016;21(1):98-106.

13. Bhaskar RK, Sah MN, Gaurav K, Bhaskar SC, Singh R, Yadav MK, et al. Prevalence and correlates of tobacco use among adolescents in the schools of Kalaiya, Nepal: a cross-sectional questionnaire based study. Tobacco induced diseases. 2016;14(1):11.

14. CBS, MoHA. Survey Report on current hard drug users in Nepal 2069.
15. Chaveepojnkamjorn W, Pichainarong N. Factors associated with alcohol consumption among male high school students in central Thailand. The Southeast Asian journal of tropical medicine and public health. 2010;41(3):735-42.

16. Granville-Garcia AF, Clementino MA, Gomes MdNC, Firmino RT, Ribeiro GLA, Siqueira MBLD. Alcohol consumption among adolescents. Ciencia \& saude coletiva. 2014;19:7-16.

17. Gobeje A. Prevalence of substance use and associated factors among preparatory students of N/Wollo Woldia Town, North East Ethiopia. Acta Scientific Nutritional Health. 2019;3(2):25-33.

18. De UDDEF, Médio REEDE. Drug use and risk factors among secondary students. Rev Latino-am Enfermagem. 2009;17(2):246-52.

19. Palamar JJ, Zhou S, Sherman S, Weitzman M. Hookah use among US high school seniors. Pediatrics. 2014;134(2):227-34.

20. Furiscal ET, Pancharuniti N, Keiwkarnka B. Alcohol drinking behavior among high school students in lowincome urban community Baguio City, Benguet Province, Philippines. Journal of Public Health and Development. 2008;6(3):155-64.

21. Gebremariam TB, Mruts KB, Neway TK. Substance use and associated factors among Debre Berhan University students, Central Ethiopia. Substance abuse treatment, prevention, and policy. 2018;13(1):13.

22. Al-Musa HM, Al-Montashri SDS. Substance abuse among male secondary school students in Abha City, Saudi Arabia: Prevalence and associated factors. Biomed Res. 2016;27(4):1364-73.

23. Duru C, Oluoha U, Okafor C, Diwe K, Iwu A. Sociodemographic determinants of psychoactive substance use among students of tertiary institutions in Imo State, Nigeria. J Addict Res Ther. 2017;8(345):2.

24. Dida N, Kassa Y, Sirak T, Zerga E, Dessalegn T. Substance use and associated factors among preparatory school students in Bale Zone, Oromia Regional State, Southeast Ethiopia. Harm reduction journal. 2014;11(1):21.

25. Mekuria M, Girma T, Birhanu A, Mergarsa A. Assessment of substance abuse and associated factors among secondary school in Ambo Town, Ethiopia. Journal of Addiction Research \& Therapy. 2019;10(3):1-14. 